\title{
1 Hidden in the deep: distinct benthic trajectories 2 call for monitoring of mesophotic reefs
}

3

4
Hernandez-Agreda $\mathrm{A}^{1^{*}}$, Sahit $\mathrm{FM}^{2}$, Englebert $\mathrm{N}^{2}$, Hoegh-Guldberg $\mathrm{O}^{2}$, Bongaerts $\mathrm{P}^{1^{*}}$

${ }^{1}$ California Academy of Sciences, San Francisco, 94118, CA, USA

${ }^{2}$ Global Change Institute and School of Biological Sciences, The University of Queensland, St Lucia, 4067 QLD, Australia

*Corresponding authors: alejhernandez@calacademy.org, pbongaerts@calacademy.org

Running title: Urgent call for mesophotic reefs monitoring

Keywords: benthic communities, coral bleaching, coral reefs, disturbances, ecosystem recovery, long-term monitoring, Mesophotic Coral Ecosystems (MCEs)

Abstract: 150 words

Whole manuscript: 2859 words

References: 40

Number of figures: 3

Number of tables: NA 


\section{Abstract}

39 Long-term monitoring studies are central to coral reef ecology and conservation management.

40 However, ongoing monitoring programs are almost exclusively focused on shallow depths, and

41 it remains unclear to what extent those are representative of the whole ecosystem. Here, we

42 present a temporal comparison (2012-2017) of directly adjacent shallow and mesophotic

43 benthic communities across seven sites from the Great Barrier Reef and Western Coral Sea.

44 We found a positive correlation initially between shallow and mesophotic coral cover, with

45 higher cover at shallow depths. However, this correlation broke down after multiple

46 disturbances, with coral cover declining only at shallow depths. Point-based tracking revealed

47 the dynamic nature of mesophotic communities, with their consistent coral cover reflecting a net

48 balance between substantial growth and mortality. Overall, the divergent trajectories highlight

49 the urgency to expand monitoring efforts into mesophotic depths, to decipher the processes

50 governing these habitats and enable better-informed management of the overall ecosystem. 


\section{Introduction}

64 Tropical coral reef ecosystems have undergone an unprecedented and accelerated decline

65 resulting from escalating local and climatic stressors (Hughes et al., 2017; Jackson et al., 2014).

66 Long-term monitoring programs play an integral role in documenting these changes and

67 identifying the underlying mechanisms of decline by discriminating between natural and

68 anthropogenic variability in ecosystem dynamics (De'ath et al., 2012; Hughes \& Connell, 1999).

69 For example, the basin-wide collapse of Caribbean reefs was recorded through such monitoring

70 efforts, attributing the decline to the cumulative stress of acute (e.g. disease outbreaks,

71 hurricanes, and thermal bleaching) and chronic disturbances (e.g. overfishing, tourism, and

72 pollution) (Gardner et al., 2003; Jackson et al., 2014). While long-term monitoring programs are

73 fewer in the Indo-Pacific, comprehensive monitoring on the Great Barrier Reef has documented

74 the detrimental impacts of cyclones, outbreaks of crown-of-thorns starfish, and thermal

75 bleaching, highlighting the extensive variability in trajectories at both small and regional spatial

76 scales (De'ath et al., 2012; Hughes et al., 2017; Osborne et al., 2011). Long-term ecological

77 monitoring is vital to improve our understanding of spatio-temporal patterns and processes and

78 subsequently forms the basis of sound conservation management.

80 Mesophotic coral ecosystems (MCEs) are a major component of the global tropical reef habitat

81 ( 50-80\%, Harris et al., (2013); Pyle \& Copus, (2019)), yet they remain largely unsurveyed and

82 therefore ignored in conservation planning (Bridge et al., 2013; Eyal et al., 2021; Rocha et al.,

83 2018). Given their distinct environmental and biological characteristics compared to shallow

84 reefs, MCEs have the potential to have distinct demographic characteristics (Kramer et al.,

85 2020; Vermeij \& Bak, 2003) and be differentially affected by disturbances (Frade et al., 2018;

86 Smith et al., 2019). However, as coral reef monitoring is almost exclusively conducted at

87 shallow depths (with the majority <15 m depth, (De'ath et al., 2012; Gardner et al., 2003)), the 
88 past and current trajectories of MCEs remain largely unknown (Bongaerts \& Smith, 2019).

89 Repeated surveys in the Caribbean have documented the possibility of substantial declines in

90 coral cover at upper mesophotic depths (30-40 m) due to storms, thermal bleaching, and lionfish

91 invasion (Hughes \& Tanner, 2000; Lesser \& Slattery, 2011). They have also highlighted how

92 responses to disturbances and overall trajectories can vary greatly over depth (Bak et al., 2005;

93 Hughes \& Jackson, 1985; Johnston et al., 2021; Smith et al., 2016). Nonetheless, long-term

94 monitoring efforts at mesophotic depths remain extremely rare, and published long-term

95 datasets from tropical mesophotic coral reefs in the Indo-Pacific appear to be lacking entirely

96 (Bongaerts et al., 2019).

98 Here, we present the results from permanent quadrats established concurrently at shallow (10

$99 \mathrm{~m})$ and upper mesophotic depths $(40 \mathrm{~m})$ in the Great Barrier Reef (GBR) and Western Coral

100 Sea (WCS) (Fig. 1). During the 4-5 years of this study (from 2012 to 2017), several major

101 disturbances (tropical cyclones and the 2016 mass bleaching) affected the communities across

102 the seven monitoring sites, providing insight into the differential cumulative impact on shallow

103 and mesophotic benthic communities. Using point-based tracking, we compare the trajectories

104 of scleractinian cover and overall benthic community structure at shallow and mesophotic

105 depths. Our results highlight different shallow and mesophotic scleractinian cover trajectories

106 and reveal initial insights on the poorly understood dynamics between shallow and deep reef

107 environments. Given the substantial area that mesophotic depths represent of the world's coral

108 reef habitat, we argue the urgency of incorporating MCEs in longitudinal monitoring efforts to

109 understand and predict their role in a world increasingly impacted by climate change.

110

\section{Methods}

112 Establishment of permanent quadrats and image collection 
113 Permanent quadrats were established in 2012 as part of the XL Catlin Seaview Survey at three

114 locations in the far northern Great Barrier Reef (Great Detached Reef, Tijou Reef, and Yonge

115 Reef) and two locations in the adjacent Western Coral Sea (Osprey Reef and Holmes Reef)

116 (Fig. 1). The establishment and monitoring of permanent quadrats were conducted under

117 permits 018-CZRS-1207626-01, 018-RRRW-131031-01 (Australian Department of the

118 Environment), G12/35281.1, and G14/37294.1 (Great Barrier Reef Marine Park Authority).

119 Monitoring was conducted following a methodology similar to that described by Bak \&

120 Nieuwland (1995). Three permanent quadrats (3 m x $3 \mathrm{~m}$ of electrical conduit PVC) were

121 secured to the reef at both $10 \mathrm{~m}$ (shallow) and $40 \mathrm{~m}$ (upper mesophotic) depth using heavy-duty

122 cable ties. At Osprey Reef, monitoring quadrats were established at three different sites, Osprey

123 Dutch Towers (DT), Osprey Bigeye Ledge (BL), and Osprey Nautilus Wall (NW) ( 4 km apart).

124 Photographs were taken using a Canon EOS 5DmIIl (with a $15 \mathrm{~mm}$ fisheye lens and a 1.4x

125 teleconverter) in an Aquatica underwater housing and a Canon PowerShot G12 (standard lens

126 at widest setting) in a Patima underwater housing, each fitted with two Sea \& Sea YS-D1

127 underwater strobes. Overview (capturing the entire quadrat) and close-up (capturing $\sim 0.5-1 \mathrm{~m}^{2}$ )

128 photographs were taken for each quadrat with both camera systems. Revisits were largely

129 determined by opportunities for sea time and further limited by weather conditions but were

130 preferably conducted in austral summer.

132 Since the initial survey of 2012 , there were three tropical cyclones (TCs) affecting the study

133 areas (Fig. 1D, Fig. S1): TC Zane from 29 April - 2 May 2013 (Category 1), TC Ita from 5-13

134 April 2014 (Category 5), TC Nathan from 9-25 March 2015 (Category 4). In addition, two large-

135 scale bleaching events occurred in the late summers of 2016 and 2017. TC Zane, and possibly

136 TC Ita for Yonge Reef, resulted in damage to shallow water quadrats at Holmes, Osprey NW,

137 and Yonge Reef (seven out of nine quadrats were affected), but quadrat outlines could be 
138 reconstructed from the original photograph except for one quadrat at Yonge Reef, which was

139 excluded from the dataset. Two locations at the Coral Sea, Bougainville Dungeons and Dragons

140 (DD) and Bougainville Crystal Plateau (CP), were established in 2017 and only included for

141 comparison (with no disturbance history). Map of locations (Fig. 1) was generated with the

142 Group Layer "GBRMPA features" (Great Barrier Reef Marine Park Authority (GBRMPA),

143 Copyright Commonwealth of Australia (2007)) and "Great Barrier Reef and Coral Sea

144 Bathymetry" data set.

146 Benthic community composition over time

147 The benthic cover was annotated using the CoralNet software (https://coralnet.ucsd.edu)

148 (Beijbom et al., 2012) following a similar approach as de Bakker et al. (2017) identifying benthic

149 categories intersected in a 225-point grid projected onto the overview quadrat photo (Fig. S2-

150 S3). The grid system allowed for tracking of individual benthic points over time, with the original

1512012 overview photo used as a reference to compensate for variation in height/angle of

152 photographing between years. The points were reidentified in overview photos of subsequent

153 years, using close-up imagery to facilitate the identification and resolve ambiguities. Individual

154 points were categorized as 'scleractinian corals', 'octocorals', 'crustose coralline algae (CCA)',

155 'Halimeda', 'macroalgae' (other than Halimeda), 'turf algae', 'sponges', 'Millepora',

156 'cyanobacteria' and 'unconsolidated substrate' (as in de Bakker et al. (2017); González-Rivero

157 et al. (2014)). 'Halimeda' was included as a separate category due to their major contribution to

158 mesophotic benthic communities (Spalding et al., 2019). The groups 'scleractinian corals' and

159 'octocorals' were further categorized based on broad family/morphological classification

160 (González-Rivero et al., 2014), to provide additional detail to benthic composition (Table S1).

161 Points showing severely (i.e., completely white) bleached tissue of 'scleractinian corals' were

162 separately classified. Other less abundant groups (e.g., tunicates, zoanthids, and anemones) 
163 were categorized as 'other'. Points were categorized as 'unidentifiable' when identification was

164 not possible (e.g., due to shading or camera angle).

Statistical analyses

167 Time and space differences in the overall benthic community and scleractinian coral cover 168 (absolute and relative change) were evaluated with a permutational multivariate analysis of 169 variance (PERMANOVA+ (Anderson et al., 2008), Type III sum of squares and 9,999 170 permutations) on Bray-Curtis (community structure) and Euclidean (coral coverage) distances.

171 Scleractinian coral cover was analyzed including bleached tissue unless otherwise indicated.

172 The data were transformed (fourth root), standardized, and analyzed under a hierarchical 173 design; Region (fixed), Site (random, nested in Region), Depth (fixed and orthogonal to Site), 174 quadrat (random and nested in the interaction SitexDepth), and Year (fixed). The highest 175 interaction of the model was excluded (Quadrat(Site(Region)xDepth)xYear). Correlations 176 between univariate variables were evaluated using the $\mathrm{R}$ vegan package (https://cran.r177 project.org/web/packages/vegan/index.html).

179 Results and Discussion

180 Over the study period, our monitoring sites experienced two major cyclones and a mass 181 bleaching event (Fig. 1D), which resulted in a significant reduction in coral cover (2012 vs 2017) 182 (Fig. 2A; Fig. S4A, Tables S2-S3). Most of the change can be attributed to the drop in 183 scleractinian coral cover at shallow depths $(10 \mathrm{~m})$ between the last two time points, after the 184 combined impacts of TC Nathan and the 2016/2017 mass bleaching event (Fig. 2A). This 185 corroborates impact patterns observed by other shallow reef surveys conducted in this region 186 (Gonzalez-Rivero et al., 2017; Hughes et al., 2017). The impacts of TCs Zane (2013) and Ita 187 (2014) were also apparent through extensive physical damage to the shallow quadrat PVC 
188 structures at Osprey NW, Holmes, and Yonge. In contrast, at mesophotic depths (40 m), no

189 significant change in absolute scleractinian coral cover was observed (Fig. 2A) despite their

190 direct adjacency to the shallow-water quadrats.

192 Given that absolute loss in coral cover is known to positively correlate with initial cover (Osborne

193 et al., 2011), we also looked at the proportional change between 2012 and 2017. This was also

194 significantly higher at shallow depths ( 38\% versus $\sim 2 \%$ at shallow and mesophotic depths

195 respectively; Fig. S4B, Tables S6). In fact, while seven sites showed a relative decrease in

196 shallow scleractinian coral cover in the final year, three out of seven sites showed a relative

197 increase in mesophotic cover (Fig. 2A, Fig. S4B). At shallow depths, the relative change in

198 scleractinian cover was also negatively correlated with initial cover (Fig. 3A), which is not

199 unexpected as higher cover may relate to larger coral structures that are more susceptible to

200 storm damage (Madin et al., 2014). However, such a correlation was not observed at

201 mesophotic depths, highlighting that the lack of decline at these depths was not merely due to

202 lower coral cover (Fig. 3A) (as the relative change was similar for high-cover sites, e.g., Osprey

203 BL and NW).

205 Initially, there was a clear positive correlation between shallow and mesophotic scleractinian 206 cover across locations, despite scleractinian coral cover varying greatly across sites and depths

207 (Fig. 3B). Although such shallow-mesophotic correlations are rarely explored, it is perhaps not

208 surprising given that the mesophotic communities occur as direct extensions of shallow reef

209 habitat, and their development may be determined by similar environmental requirements as

210 their shallow-water counterparts (Gress et al., 2018). For example, hard substrate availability

211 ultimately determines the potential for scleractinian coral cover and is strongly determined by

212 local geomorphological features that can extend from shallow to mesophotic depths (Sherman 
213 et al., 2019). Similarly, certain chronic pressures such as sedimentation, ocean acidification,

214 pollution, disease outbreaks, and invasive species are expected to impact coral communities

215 across broad depth ranges (Bak et al., 2005; Smith et al., 2019), further contributing to this

216 shallow-mesophotic correlation. After the disturbances (2016/2017), this correlation broke down

217 as the acute disturbances predominantly impacted shallow scleractinian cover, with mesophotic

218 scleractinian cover remaining at similar levels (Fig. 3B). Although the pre-disturbance correlation

219 indicates a clear relationship between shallow-mesophotic coral cover, the post-disturbance

220 shift highlights how the differential impact of disturbances over depth can lead to diverging

221 benthic trajectories.

223 Changes in coral cover represent a net balance of gains (through e.g. coral growth and

224 recruitment) and losses (through e.g. mortality and displacement) (Brito-Millán et al., 2019;

225 Hughes \& Jackson, 1985). Point-based tracking of the benthic community within our permanent

226 quadrats revealed that the relatively consistent cover at mesophotic depths is driven by near-

227 identical gains and losses (Fig. 2B, $6 \pm 1.1 \%$ and $5.7 \pm 0.9 \%$, respectively, excluding Yonge)

228 resulting in a net change close to zero. Although the hypothesized stability of MCEs is often

229 colloquially interpreted as these ecosystems being more static (Smith et al., 2019), early

230 quadrat-based observations already pointed towards their potentially dynamic nature (Bak et al.,

231 2005; Liddell \& Avery, 2000). Visual observations of the quadrats support this notion, with

232 roughly a third of scleractinian coral colonies suffering partial mortality and many examples of

233 complete colony displacements (particularly in tabular Acropora colonies). At the same time,

234 considerable growth rates were observed for both tabular and plating corals at mesophotic

235 depths, with anecdotal measurements including radial extension rates of $\sim 2-4 \mathrm{~cm} /$ year in

236 Acropora, Montipora, Mycedium, and Pachyseris. We also observed substantial shifts in

237 community structure, with Acroporidae and Poritidae decreasing in coverage over time at

238 mesophotic depths (7.4\% and 7.7\%, respectively), while all other families, Faviidae-Mussidae, 
239 Pocilloporidae, Merulinidae, Agariciidae, and Fungiidae, increased in coverage between $5 \%$ to

$24037 \%$ (Fig. S5). Regarding the morphological composition of the mesophotic reef, branching and

241 plating morphologies increased $51 \%$ and $19 \%$ respectively (to their initial coverage), whereas

242 massive, encrusting, and corymbose morphologies decreased between 2 and 24\% (Fig. S6).

244 In terms of the overall benthic structure, Scleractinia, Millepora (fire coral), crustose coralline

245 algae, and unconsolidated substrate drove the overall differences between depths (Fig. S7-S8).

246 Shallow reef communities showed increases in turf algae, and decreases in coral cover, similar

247 to trajectories observed in many disturbance-affected reefs (Jackson et al., 2014). Macroalgae

248 (primarily Halimeda and fleshy algae) dominated and were major drivers of change in

249 mesophotic communities, although coverage and trajectories were highly variable across sites

250 (Fig. 2C). For example, at Osprey DT, Halimeda doubled its coverage in a single year (2012-

251 2013), whereas in Osprey NW and Holmes was almost extirpated by 2017. At Holmes, the

252 disappearance of Halimeda coincided with an outbreak of Microdictyon (from $25 \%$ to $67 \%$ ),

253 which colonizes mesophotic reefs by forming large monospecific mats (Kahng et al., 2017;

254 Spalding et al., 2019). Macroalgae dominance in mesophotic reefs have been previously

255 reported in the Western Atlantic and Indo-Pacific, playing a fundamental role in the

256 geomorphology of mesophotic habitats by consolidating and modifying the complexity of the

257 substrate (Spalding et al., 2019). Observed changes in macroalgae abundance can likely be

258 attributed to seasonal fluctuations in temperature and nutrients related to upwelling intensity, to

259 which macroalgae species can be responsive (Spalding et al., 2019).

260 Overall, these results demonstrate the importance of concurrent monitoring reefs at shallow and

261 mesophotic depths and yielded some critical insights: (1) The initial correlation between shallow

262 and mesophotic cover highlighted the connection between benthic communities at different

263 depths, a fundamental observation that warrants further investigation to understand the 
264 underlying drivers of this relationship. (2) The observed breakdown of the correlation following

265 disturbances led to divergent trajectories in directly adjacent communities (shallow and

266 mesophotic), challenging us to question whether and how such relationships naturally rebound.

267 (3) Lastly, in contrast to their conventional view as slow-growing and "static", the observed

268 dynamic nature of scleractinian coral communities at mesophotic depths highlights the rapid

269 changes these communities can undergo independent from shallow communities. Although

270 monitoring efforts at mesophotic depths are inherently more costly and logistically complicated,

271 they are gradually becoming more accessible through advances in underwater (Armstrong et

272 al., 2019; Pyle, 2019) and imaging technologies (e.g. Bongaerts et al. (2021); Ferrari et al.

273 (2016)). We consider that such efforts need to be prioritized given the major spatial extent of

274 these communities and their role in the overall coral reef ecosystem. Only through sustained

275 observations at these depths will we get the insights needed to understand the fundamental

276 ecological processes that govern these ecosystems, and ensure that we maximize our ability to

277 protect them into the future.

279 Acknowledgements

280 We thank David Whillas, Kyra Hay and Paul Muir for their help with the initial establishment and

281 rephotographing of the permanent quadrats. For field support, we would like to thank Jaap

282 Barendrecht, Linda Tonk, David Aguirre, Pedro Frade, Manuel Gonzalez-Rivero, David Harris,

283 Susie Green, Erin McFadden, Steve Lindfield, Sara Naylor, as well as Underwater Earth, The

284 Ocean Agency, and crews from Reef Connections, Mike Ball Dive Expeditions, SY Ethereal,

285 and the Waitt Foundation. We thank Juan J. Cruz-Motta for comments regarding data analysis.

286 This project was supported (in chronological order) by the XL Catlin Seaview Survey (2012-

287 2014; funded by the XL Catlin Group in partnership with Underwater Earth and The University of

288 Queensland), an Australian Research Council Discovery Early Career Researcher Award 
(2016-2018; DE160101433), and the Hope for Reefs Initiative at the California Academy of

290 Sciences. Substantial sea time was generously provided by the Waitt Foundation and the Joy

291 Foundation.

\section{Author contributions}

294 PB, NE and OHG conceived and designed the study. PB and NE conducted the fieldwork. FS 295 conducted the image classification. AHA, FS and PB conducted and contributed to the 296 analyses. AHA, PB and FS wrote the manuscript and all the authors contributed to the edits.

\section{Data accessibility statement}

299 Annotation and temperature data will be available through

300 https://github.com/pimbongaerts/monitoring.

\section{References}

303 Anderson, M. J., Gorley, R. N., \& Clarke, K. R. (2008). PERMANOVA + for PRIMER: Guide to Software and Statistical Methods (First edition). PRIMER-E.

Armstrong, R. A., Pizarro, O., \& Roman, C. (2019). Underwater robotic technology for imaging Mesophotic Coral Ecosystems. In Y. Loya, K. A. Puglise, \& T. C. L. Bridge (Eds.), Mesophotic Coral Ecosystems (Vol. 12, pp. 973-988). Springer International Publishing. https://doi.org/10.1007/978-3-319-92735-0_51

312 Bak, R. P. M., Nieuwland, G., \& Meesters, E. H. (2005). Coral reef crisis in deep and shallow reefs: 30 years of constancy and change in reefs of Curaçao and Bonaire. Coral Reefs, 24(3), 475-479. https://doi.org/10.1007/s00338-005-0009-1 
315 Beijbom, O., Edmunds, P. J., Kline, D. I., Mitchell, B. G., \& Kriegman, D. (2012). Automated annotation of coral reef survey images. 2012 IEEE Conference on Computer Vision and Pattern Recognition, 1170-1177. https://doi.org/10.1109/CVPR.2012.6247798

Bongaerts, P., Dubé, C. E., Prata, K. E., Gijsbers, J. C., Achlatis, M., \& Hernandez-Agreda, A. (2021). Reefscape Genomics: Leveraging advances in 3D imaging to assess fine-scale patterns of genomic variation on coral reefs. Frontiers in Marine Science, 8, 638979. https://doi.org/10.3389/fmars.2021.638979

Bongaerts, P., Perez-Rosales, G., Radice, V. Z., Eyal, G., Gori, A., Gress, E., Hammerman, N. M., Hernandez-Agreda, A., Laverick, J., Muir, P., Pinheiro, H., Pyle, R. L., Rocha, L., Turner, J. A., \& Booker, R. (2019). Mesophotic.org: A repository for scientific information on mesophotic ecosystems. Database, 2019, baz140. https://doi.org/10.1093/database/baz140

Bongaerts, P., \& Smith, T. B. (2019). Beyond the "Deep Reef Refuge" Hypothesis: A conceptual framework to characterize persistence at depth. In Y. Loya, K. A. Puglise, \& T. C. L. Bridge (Eds.), Mesophotic Coral Ecosystems (Vol. 12, pp. 881-895). Springer

de Bakker, D. M., van Duyl, F. C., Bak, R. P. M., Nugues, M. M., Nieuwland, G., \& Meesters, E. H. (2017). 40 Years of benthic community change on the Caribbean reefs of Curaçao and Bonaire: The rise of slimy cyanobacterial mats. Coral Reefs, 36(2), 355-367. https://doi.org/10.1007/s00338-016-1534-9 International Publishing. https://doi.org/10.1007/978-3-319-92735-0_45

Bridge, T. C. L., Hughes, T. P., Guinotte, J. M., \& Bongaerts, P. (2013). Call to protect all coral reefs. Nature Climate Change, 3(6), 528-530. https://doi.org/10.1038/nclimate1879

Brito-Millán, M., Vermeij, M., Alcantar, E., \& Sandin, S. (2019). Coral reef assessments based on cover alone mask active dynamics of coral communities. Marine Ecology Progress Series, 630, 55-68. https://doi.org/10.3354/meps13128

343 Eyal, G., Laverick, J. H., Bongaerts, P., Levy, O., \& Pandolfi, J. M. (2021). Mesophotic Coral Ecosystems of the Great Barrier Reef are understudied and underexplored. Frontiers in Marine Science, 8, 622856. https://doi.org/10.3389/fmars.2021.622856

Ferrari, R., McKinnon, D., He, H., Smith, R., Corke, P., González-Rivero, M., Mumby, P., \& Upcroft, B. (2016). Quantifying Multiscale Habitat Structural Complexity: A Cost-Effective 
Framework for Underwater 3D Modelling. Remote Sensing, 8(2), 113. https://doi.org/10.3390/rs8020113

Frade, P. R., Bongaerts, P., Englebert, N., Rogers, A., Gonzalez-Rivero, M., \& Hoegh-Guldberg, O. (2018). Deep reefs of the Great Barrier Reef offer limited thermal refuge during mass coral bleaching. Nature Communications, 9(1), 3447. https://doi.org/10.1038/s41467018-05741-0

Gardner, T. A., Côté, I. M., Gill, J. A., Grant, A., \& Watkinson, A. R. (2003). Long-term regionwide declines in Caribbean corals. Science, 301(5635), 958-960. https://doi.org/10.1126/science.1086050

Gonzalez-Rivero, M., Rodriguez-Ramirez, A., Tonk, L., Puotinen, M., Heron, S. F., Skirving, W. J., Kennedy, E. V., Ridgway, T., \& Hoegh-Guldberg, O. (2017). The effect of cumulative stress on reef slope coral communities in the far northern and northern Great Barrier Reef: 2012 to 2016 (p. 44). The Global Change Institute.

Gress, E., Arroyo-Gerez, M. J., Wright, G., \& Andradi-Brown, D. A. (2018). Assessing mesophotic coral ecosystems inside and outside a Caribbean marine protected area. Royal Society Open Science, 5(10), 180835. https://doi.org/10.1098/rsos.180835

Harris, P. T., Bridge, T. C. L., Beaman, R. J., Webster, J. M., Nichol, S. L., \& Brooke, B. P. (2013). Submerged banks in the Great Barrier Reef, Australia, greatly increase available coral reef habitat. ICES Journal of Marine Science, 70(2), 284-293. https://doi.org/10.1093/icesjms/fss 165

Hughes, T. P., \& Connell, J. H. (1999). Multiple stressors on coral reefs: A long -term perspective. Limnology and Oceanography, 44, 932-940. https://doi.org/10.4319/lo.1999.44.3_part_2.0932

Hughes, T. P., \& Jackson, J. B. C. (1985). Population dynamics and life histories of foliaceous corals. Ecological Monographs, 55(2), 141-166. https://doi.org/10.2307/1942555 A. H., Babcock, R. C., Beger, M., Bellwood, D. R., Berkelmans, R., Bridge, T. C., Butler, I. R., Byrne, M., Cantin, N. E., Comeau, S., Connolly, S. R., Cumming, G. S., Dalton, S. 
J., Diaz-Pulido, G., ... Wilson, S. K. (2017). Global warming and recurrent mass bleaching of corals. Nature, 543(7645), 373-377. https://doi.org/10.1038/nature21707

Hughes, T. P., \& Tanner, J. E. (2000). Recruitment failure, life histories, and long-term decline of Caribbean corals. Ecology, 81(8), 14.

Jackson, J., Donovan, M., Cramer, K., \& Lam, V. (2014). Status and trends of Caribbean Coral Reefs: 1970-2012.

Johnston, M. A., O'Connell, K., Blakeway, R. D., MacMillan, J., Nuttall, M. F., Hu, X., Embesi, E. L., Hickerson, E. L., \& Schmahl, G. P. (2021). Long-term monitoring at East and West Flower Garden Banks: 2019 Annual report (National Marine Sanctuaries Conservation Series ONMS-21-02, p. 101). U.S. Department of Commerce, National Oceanic and Atmospheric Administration, Flower Garden Banks National Marine Sanctuary.

Kahng, S., Copus, J. M., \& Wagner, D. (2017). Mesophotic Coral Ecosystems. In S. Rossi, L. Bramanti, A. Gori, \& C. Orejas (Eds.), Marine Animal Forests (pp. 1-22). Springer International Publishing. https://doi.org/10.1007/978-3-319-17001-5_4-1

Kramer, N., Tamir, R., Eyal, G., \& Loya, Y. (2020). Coral morphology portrays the spatial distribution and population size-structure along a 5-100 m depth gradient. Frontiers in Marine Science, 7, 615. https://doi.org/10.3389/fmars.2020.00615 depths associated with lionfish (Pterois volitans) invasion on a Bahamian coral reef. Biological Invasions, 13(8), 1855-1868. https://doi.org/10.1007/s10530-011-0005-z

Liddell, W. D., \& Avery, W. E. (2000). Temporal change in hard substrate communities 10-250 $\mathrm{m}$, the Bahamas. Proceedings 9 International Coral Reef Symposium, 2, 6.

Madin, J. S., Baird, A. H., Dornelas, M., \& Connolly, S. R. (2014). Mechanical vulnerability explains size-dependent mortality of reef corals. Ecology Letters, 17(8), 1008-1015. https://doi.org/10.1111/ele.12306

Osborne, K., Dolman, A. M., Burgess, S. C., \& Johns, K. A. (2011). Disturbance and the dynamics of coral cover on the Great Barrier Reef (1995-2009). PLoS ONE, 6(3), e17516. https://doi.org/10.1371/journal.pone.0017516

Pyle, R. L. (2019). Advanced technical diving. In Y. Loya, K. A. Puglise, \& T. C. L. Bridge (Eds.), Mesophotic Coral Ecosystems (Vol. 12, pp. 959-972). Springer International Publishing.

412 Pyle, R. L., \& Copus, J. M. (2019). Mesophotic Coral Ecosystems: Introduction and Overview. In 413 Y. Loya, K. A. Puglise, \& T. C. L. Bridge (Eds.), Mesophotic Coral Ecosystems (Vol. 12, 
Rocha, L. A., Pinheiro, H. T., Shepherd, B., Papastamatiou, Y. P., Luiz, O. J., Pyle, R. L., \& Bongaerts, P. (2018). Mesophotic coral ecosystems are threatened and ecologically distinct from shallow water reefs. Science, 361(6399), 281-284. https://doi.org/10.1126/science.aaq1614

Sherman, C. E., Locker, S. D., Webster, J. M., \& Weinstein, D. K. (2019). Geology and Geomorphology. In Y. Loya, K. A. Puglise, \& T. C. L. Bridge (Eds.), Mesophotic Coral Ecosystems (Vol. 12, pp. 849-878). Springer International Publishing. https://doi.org/10.1007/978-3-319-92735-0_44

Smith, T. B., Gyory, J., Brandt, M. E., Miller, W. J., Jossart, J., \& Nemeth, R. S. (2016). Caribbean Mesophotic Coral Ecosystems are unlikely climate change refugia. Global Change Biology, 22(8), 2756-2765. https://doi.org/10.1111/gcb.13175

Smith, T. B., Holstein, D. M., \& Ennis, R. S. (2019). Disturbance in Mesophotic Coral Ecosystems and linkages to conservation and management. In Y. Loya, K. A. Puglise, \& T. C. L. Bridge (Eds.), Mesophotic Coral Ecosystems (Vol. 12, pp. 911-929). Springer International Publishing. https://doi.org/10.1007/978-3-319-92735-0_47

Spalding, H. L., Amado-Filho, G. M., Bahia, R. G., Ballantine, D. L., Fredericq, S., Leichter, J. J., Nelson, W. A., Slattery, M., \& Tsuda, R. T. (2019). Macroalgae. In Y. Loya, K. A. Puglise, \& T. C. L. Bridge (Eds.), Mesophotic Coral Ecosystems (Vol. 12, pp. 507-536). Springer International Publishing. https://doi.org/10.1007/978-3-319-92735-0_29 

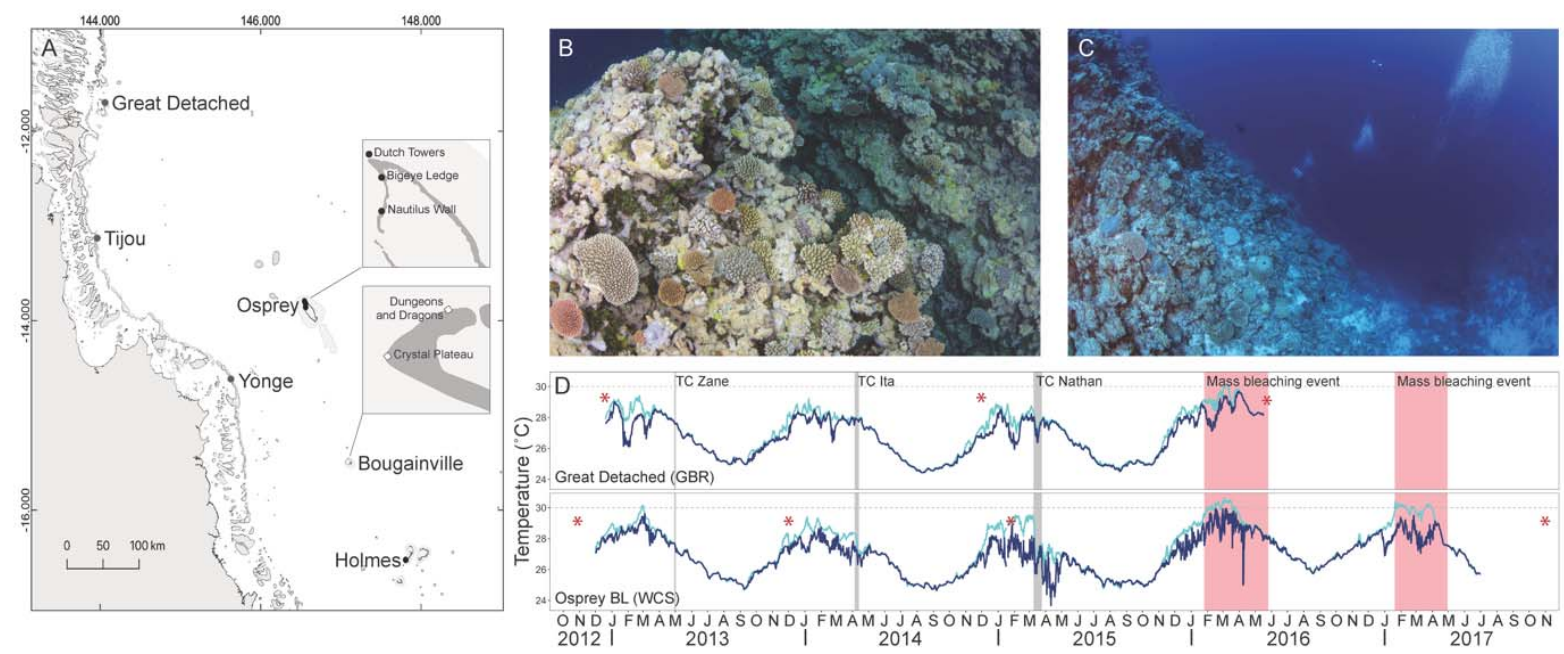

453 Figure 1. Locations and temperature profiles of the monitoring sites. (A) Map detailing the

454 locations of the sampling sites. Great Barrier Reef (GBR) sites are indicated as grey dots,

455 Western Coral Sea (WCS) reef sites with black dots. (B) Example of a shallow reef habitat (10

$456 \mathrm{~m}$ ) from Osprey DT. (C) Example of a mesophotic reef habitat (40 m) from Osprey DT. (D) Daily 457 mean temperature profiles from one of the Great Barrier Reef (Great Detached) and Western 458 Coral Sea (Osprey BL) locations between 2012 and 2017. The timeline also indicated the 459 occurrence of three Tropical Cyclones (TCs) in grey and two mass bleaching events in red. 460 Sampling dates are indicated with red asterisks. Daily mean temperature profiles of all the 461 sampling sites in Fig. S1. 
A

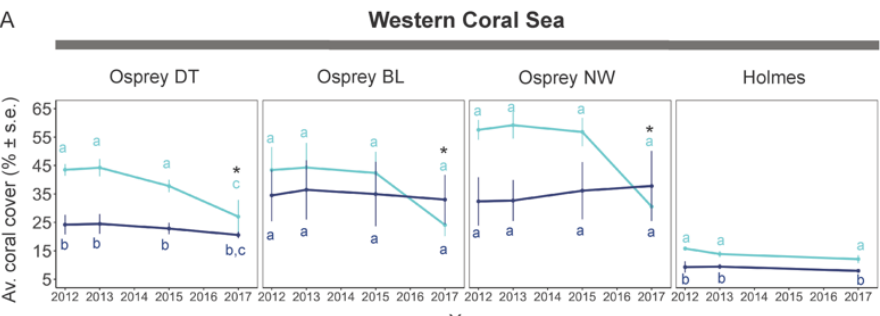

B

2012-2017
2012-2017

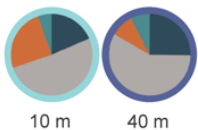

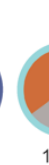

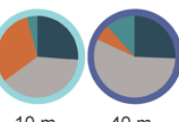

No change: Scleractinian

Gain: Non Scleractinian $\rightarrow$ Scleractinian

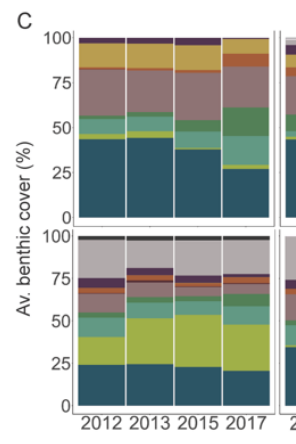

Scleractinian Halimeda spp.

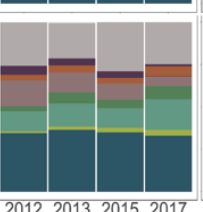

Other macroalgae

- Turf algae

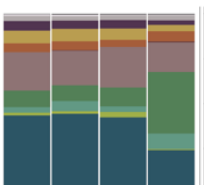

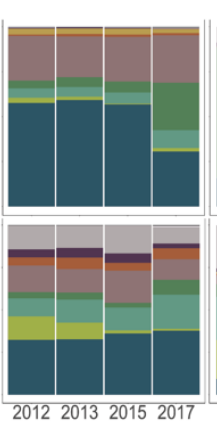
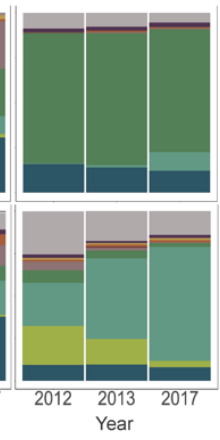

CCA

Dyanobacteria
2012-2017

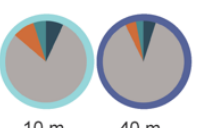

$40 \mathrm{~m}$

Sponges Millepora spp.

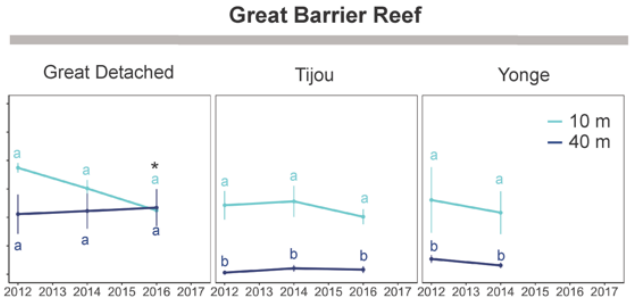

Year
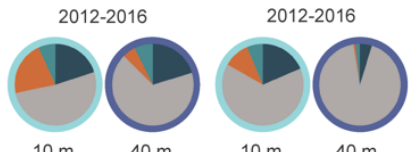

2012-2014

No change: Non - Scleractinian

Loss: Scleractinian $\rightarrow$ Non - Scleractinian
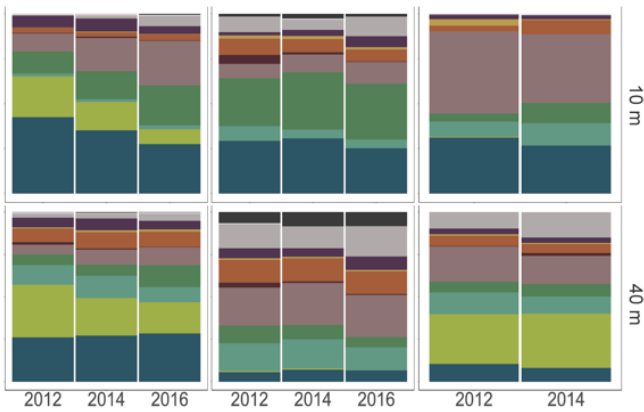

Octocorals

Unconsolidated substrate

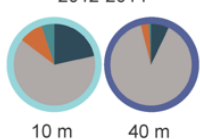

Non Scleractinian

Unidentifiable

464 Figure 2. Changes in scleractinian coral cover and benthic community structure across time. (A) 465 Scleractinian coral cover over time at shallow $(10 \mathrm{~m})$ and mesophotic $(40 \mathrm{~m})$ depths. Letters 466 indicate significant differences between depths and the interaction DepthxYear $(p<0.05$, Table 467 S4), and asterisks overall differences between 2012 and 2017 ( $p<0.05$, Table S5). Error bars 468 indicate standard error across replicate quadrats (s.e.). (B) Gains and losses in scleractinian 469 cover based on point-based tracking (225 points per quadrat) between 2012 and 2016/2017 470 (raw data in Fig. S2-S3). (C) Changes in community structure at shallow (10 m) and mesophotic 471 (40 m) depths. "Other macroalgae" represent all macroalgae species excluding Halimeda spp 472 (listed separately). "CCA" stands for crustose coralline algae. 

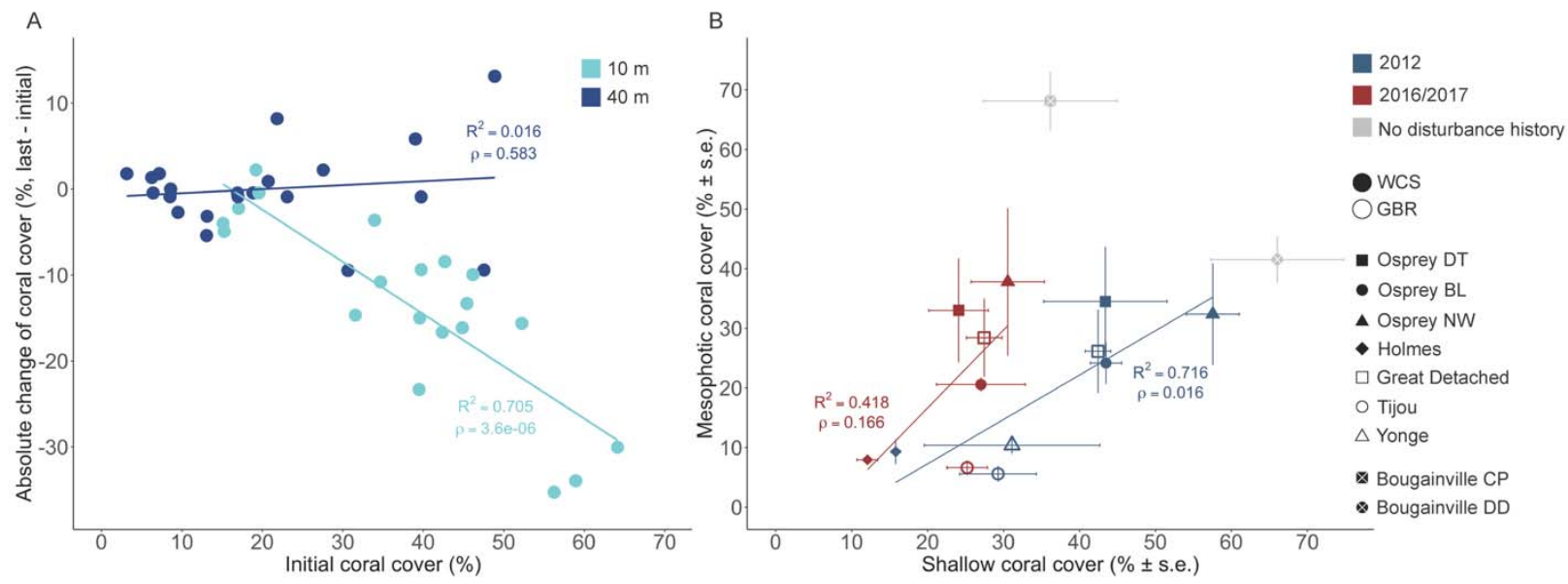

475 Figure 3. Changes and relationships between scleractinian coral cover at shallow (10 m) and 476 mesophotic $(40 \mathrm{~m})$ depths. (A) Correlation between the initial scleractinian coral cover (2012) 477 and the absolute change over time. (B) Correlation between shallow and mesophotic coral 478 cover at the beginning of the study period (2012) and at the end, after several disturbances 479 (2016/2017). Bougainville DD and Bougainville CP were only surveyed at the last time point 480 (2017). Error bars indicate standard error across replicate quadrats (s.e.). 